\title{
The novel JNK inhibitor AS602801 inhibits cancer stem cells in vitro and in vivo
}

\author{
Masashi Okada ${ }^{1}$, Kenta Kuramoto ${ }^{1}$, Hiroyuki Takeda ${ }^{1,2}$, Hikaru Watarai ${ }^{1,3}$, \\ Hirotsugu Sakaki ${ }^{1,4}$, Shizuka Seino ${ }^{1,5}$, Manabu Seino ${ }^{1,4}$, Shuhei Suzuki,2 and \\ Chifumi Kitanaka ${ }^{1,5}$ \\ ${ }^{1}$ Department of Molecular Cancer Science, Yamagata University School of Medicine, Yamagata, Japan \\ 2 Department of Clinical Oncology, Yamagata University School of Medicine, Yamagata, Japan \\ ${ }^{3}$ Second Department of Surgery, Yamagata University School of Medicine, Yamagata, Japan \\ ${ }^{4}$ Department of Obstetrics and Gynecology, Yamagata University School of Medicine, Yamagata, Japan \\ ${ }^{5}$ Research Institute for Promotion of Medical Sciences, Yamagata University Faculty of Medicine, Yamagata, Japan \\ Correspondence to: Chifumi Kitanaka, email: ckitanak@med.id.yamagata-u.ac.jp \\ Keywords: cancer initiating cells, C-Jun N-terminal kinase, drug repositioning, serial transplantation assay, xenograft \\ Received: August 27, 2015 \\ Accepted: March 16, 2016 \\ Published: March 26, 2016
}

\section{ABSTRACT}

A phase 2 clinical trial investigating the efficacy and safety of AS602801, a newly developed JNK inhibitor, in the treatment of inflammatory endometriosis is complete. We are now examining whether AS602801 acts against human cancer cells in vitro and in vivo. In vitro, AS602801 exhibited cytotoxicity against both serum-cultured non-stem cancer cells and cancer stem cells derived from human pancreatic cancer, non-small cell lung cancer, ovarian cancer and glioblastoma at concentrations that did not decrease the viability of normal human fibroblasts. AS602801 also inhibited the self-renewal and tumor-initiating capacity of cancer stem cells surviving AS602801 treatment. Cancer stem cells in established xenograft tumors were reduced by systemic administration of AS602801 at a dose and schedule that did not adversely affect the health of the tumor-bearing mice. These findings suggest AS602801 is a promising anti-cancer stem cell agent, and further investigation of the utility of AS602801 in the treatment of cancer seems warranted.

\section{INTRODUCTION}

The c-Jun $\mathrm{NH}_{2}$-terminal kinases (JNKs) belong to the mitogen-activated protein (MAP) kinase family. JNK relays, amplifies, and integrates signals from a diverse range of extracellular stimuli, and are thus involved in important cellular processes such as proliferation, apoptosis, and differentiation [1-3]. As such, JNK has been implicated in a number of human diseases, including cancer; the growing body of evidence from animal and human studies suggests a critical role for aberrant activation of JNK in cancer development, and JNK is drawing increasing attention as a promising target of anticancer therapy [4-8].

Although the exact mechanisms by which JNK contributes to cancer development and maintenance remain largely unknown, we have demonstrated that JNK is a key molecule in the maintenance of glioma stem cells and, most importantly, is a viable molecular target for glioma stem cell-directed therapy [9, 10]. Furthermore, we have revealed that this key role of JNK is not unique to glioblastoma, but is shared by other malignancies, such as ovarian, pancreatic, and possibly lung cancers, suggesting that JNK inhibitors like SP600125 could prove effective against different human cancers through the elimination of cancer stem cells [11-13]. However, the safety profile of SP600125 in humans remains unknown.

A phase 2 clinical trial (NCT 01630252) of AS602801, a newly developed, orally-active, ATPcompetitive inhibitor of JNK, was recently completed to investigate its efficacy and safety in the treatment of inflammatory endometriosis $[14,15]$. Although there has been one study of the immunomodulatory effect of AS602801, the anticancer effects of AS602801 have not been reported to date [15]. Here, we examined the effects of AS602801 on human cancer cells in vitro and in vivo 
to determine whether AS602801 might act as a novel anticancer agent.

\section{RESULTS}

\section{AS602801 shows selective cytotoxic activity against both serum-cultured cancer cells and cancer stem cells in vitro}

To determine the range of concentrations of AS602801 that are not toxic to non-neoplastic cells, we first examined the viability of IMR90 normal human fibroblasts after treating them with different concentrations of AS602801. IMR90 cells tolerated up to $10 \mu \mathrm{M}$ AS602801; we chose a maximum concentration of 7.5 $\mu \mathrm{M}$ for subsequent in vitro experiments (Figure 1A). To avoid underestimating cell death, we also analyzed cell death in situ using the fluorescent vital dye propidium iodide (PI) instead of trypan blue to reduce the loss of dead cells during the cell collecting procedure. Using this in situ method, we confirmed that $7.5 \mu \mathrm{M}$ AS602801 did not appreciably induce the death of IMR90 cells (Figure 1B). We then examined whether AS602801 had anticancer effects. To this end, we treated three serum-cultured human cancer cell lines (PANC-1, pancreatic cancer; A594, lung cancer; A2780, ovarian cancer) with AS602801 and examined their growth. AS602801 treatment induced cell death and accordingly decreased the number of viable cells in all three cell lines in a dose-dependent manner, suggesting that AS602801 may have selective cytotoxic activity against neoplastic cells (Figure 1A and 1B). We next investigated whether cancer stem cells derived from these cell lines (PANC-1 CSLCs, A549 CSLCs, and A2780 CSLCs) were resistant to AS602801-induced cell death. AS602801 induced cell death in these cells as efficiently as in the original cell lines, suggesting that the cancer stem cell and non-cancer stem cell subpopulations within a cell line are equally sensitive to AS602801 (Figure 2A and $2 \mathrm{~B}$ ). GS-Y01 cells, which are patient-derived glioma stem cells, were also tested to examine whether AS602801 has cytotoxic activity against cells established directly from patient tumor tissues. AS602801 also had cytotoxic activity against GS-Y01 cells (Figure 2A and 2B).

\section{AS602801 inhibits self-renewal capacity in surviving cancer stem cells}

Since our previous studies indicated that SP600125 could inhibit the self-renewal capacity of cancer stem cells without causing cell death, we next asked whether selfrenewal capacity was also inhibited in cancer stem cells that survived AS602801 treatment. To this end, we first examined the effect of AS602801 treatment on the cell surface expression of CD133, a cancer stem cell marker for various cancer types [16-18]. When the cancer stem cell fraction surviving AS602801 treatment was analyzed by flow cytometry, the proportion of CD133-positive cells decreased in a dose-dependent manner in all cancer stem cell lines examined (Figure 3A). Subsequent analysis revealed that the levels of other stem cell markers, such as Sox2, Nanog, and Bmi1, were decreased similarly to CD133 (Figure 3B). Interestingly, levels of c-Myc, a key pluripotency factor implicated in the maintenance of glioma and other cancer stem cells [19-21], decreased after AS602801 treatment (Figure 3B). In addition to the marker analyses, we examined the effect of AS602801 on the ability of cancer stem cells to self-renew as spheres. When viable cells surviving AS602801 treatment were subjected to a sphere-formation assay in the absence of AS602801, cancer stem cells treated with AS602801 formed fewer spheres compared to control cells (Figure 4). Altogether, these results indicated that, in addition to its cytotoxic activity against cancer stem cells, AS602801 inhibits the self-renewal capacity of cancer stem cells surviving AS602801 treatment.

\section{AS602801 inhibits tumor-initiating capacity in surviving cancer stem cells}

We next investigated whether cancer stem cells surviving AS602801 treatment also lost tumor-initiating capacity, which is another key feature characterizing cancer stem cells. When an equal number of viable PANC1 CSLCs was implanted subcutaneously into nude mice after treatment with or without AS602801, cells treated with AS602801 failed to perpetuate tumor growth, whereas untreated cells invariably formed tumors that continued to grow progressively (Figure 5A). Intriguing, all tumors initially formed by AS602801-treated PANC-1 CSLCs eventually regressed spontaneously. Thus, AS602801 deprived the cancer stem cells of their capacity to selfrenew indefinitely and support progressive tumor growth, without interfering with their engraftment in nude mice. AS602801 treatment similarly prevented tumor initiation by A2780 CSLCs (Figure 5B). These results demonstrated that AS602801 could inhibit the tumor-initiating capacity of cancer stem cells that survived AS602801 treatment.

\section{Systemic administration of AS602801 reduces tumor-initiating cancer stem cells in vivo}

We next sought to determine whether AS602801 could reduce cancer stem cell numbers in vivo. Since mice tolerated daily administration of $40 \mathrm{mg} / \mathrm{kg}$ AS602801 (Figure 5C), we treated mice bearing subcutaneous tumors formed by implantation of PANC-1 CSLCs (primary tumors) with or without $40 \mathrm{mg} / \mathrm{kg}$ AS602801 daily for 10 consecutive days, after which subcutaneous tumors 


\section{$\mathbf{A}_{\underline{\text { PANC-1 }}}$}

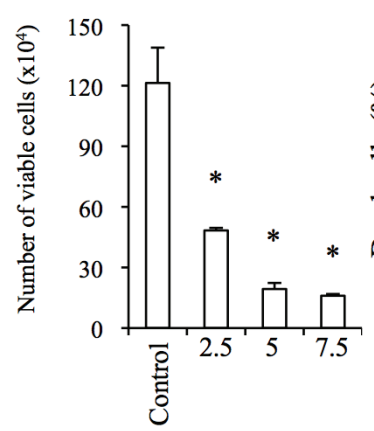

$\underline{\mathrm{A549}}$
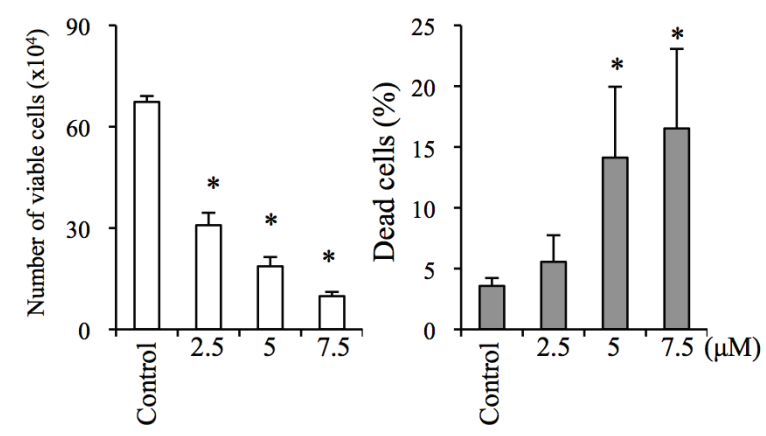

B
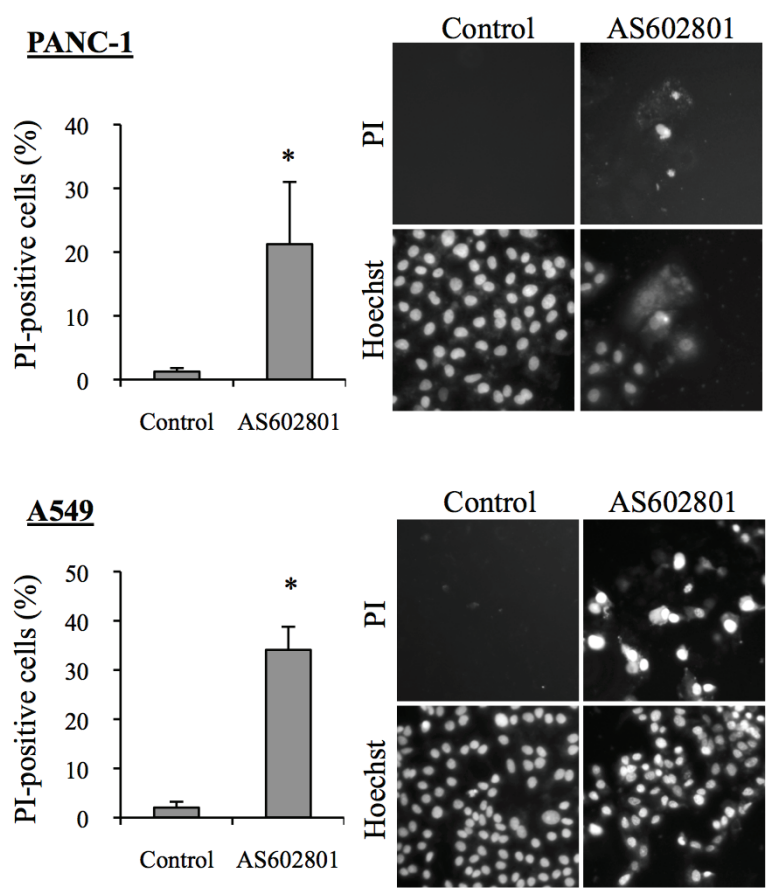

B

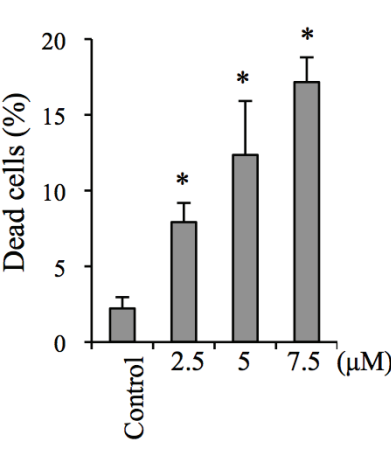

\section{$\underline{\mathbf{A 2 7 8 0}}$}

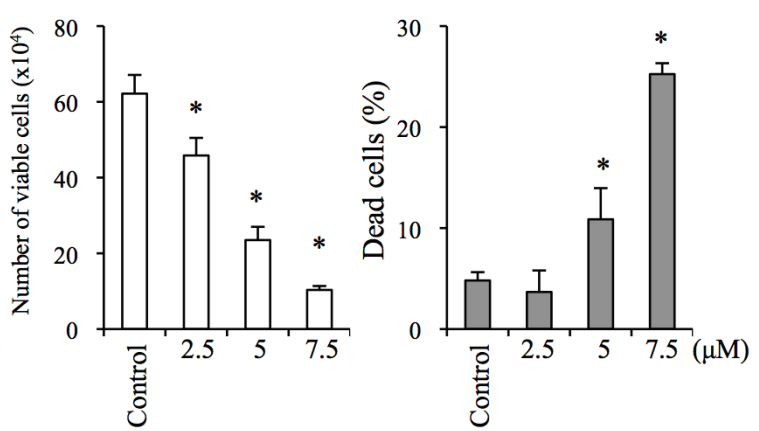

\section{$\underline{\operatorname{IMR90}}$}
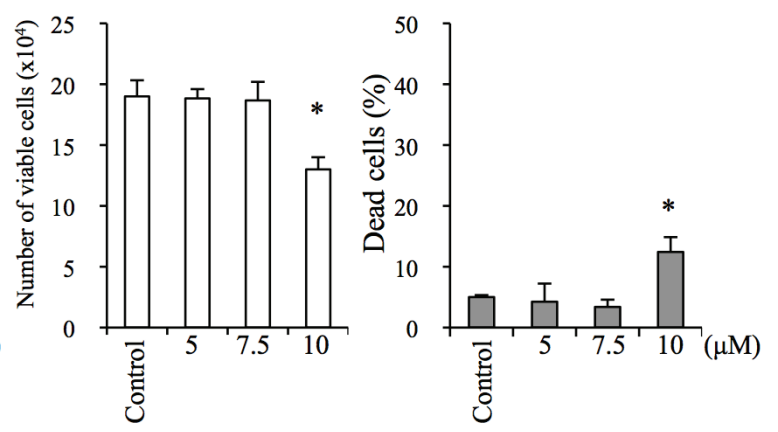
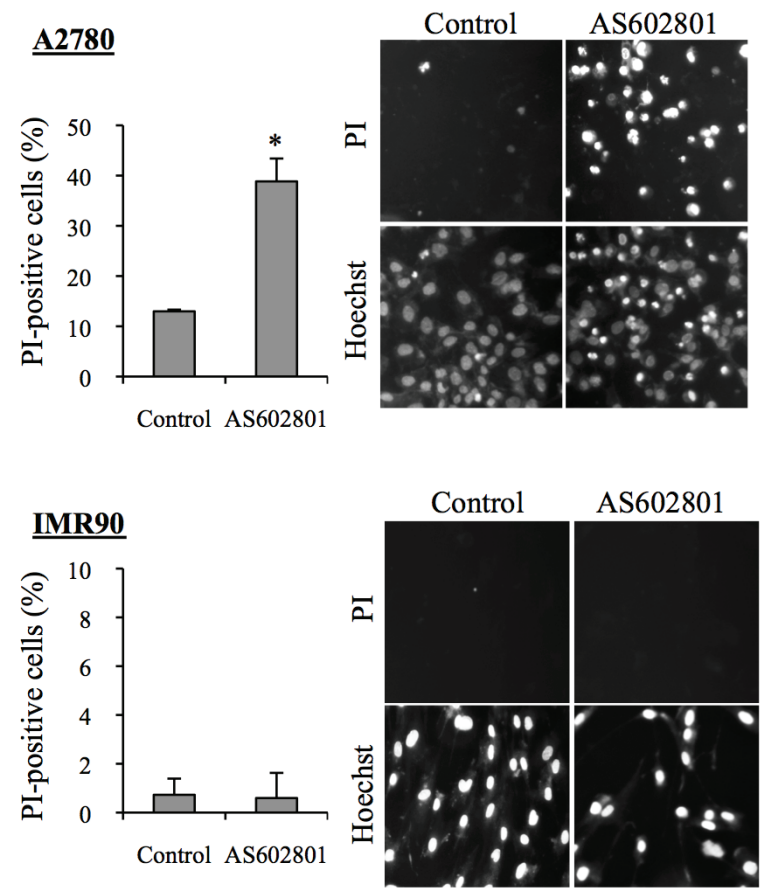

Figure 1: AS602801 induces selective cytotoxicity in serum-cultured human cancer cells. A. PANC-1, A2780, and A549 human cancer cells and IMR90 human normal fibroblasts were treated without (Control) or with the indicated concentrations of AS602801 for 3 days. The number of viable cells (left panels) and the percentage of dead cells (right panels) were determined using trypan blue as a vital dye. B. Cells were subjected to cell death analysis using propidium iodide (PI) as a vital dye after treatment without (Control) or with 7.5 $\mu \mathrm{M}$ AS602801. Left, the percentage of PI-positive (dead) cells relative to Hoechst-positive (total) cells was determined. Right, representative fluorescence images of PI- (upper rows) and Hoechst-positive cells (lower rows) are shown. Values in the graphs represent the mean + SD from three independent experiments. ${ }^{*} P<0.05$. 
were excised for serial transplantation and stem cell marker analysis. For the serial transplantation analysis, we transplanted different numbers of dissociated cells

\section{$\mathbf{A}$}
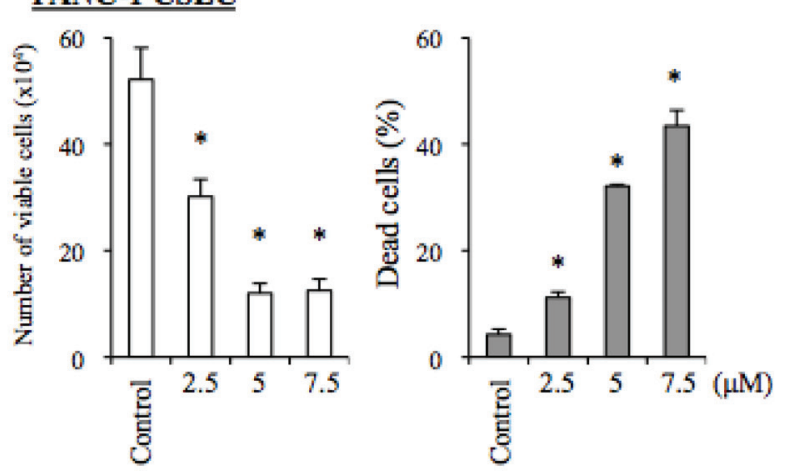

A549 CSLC

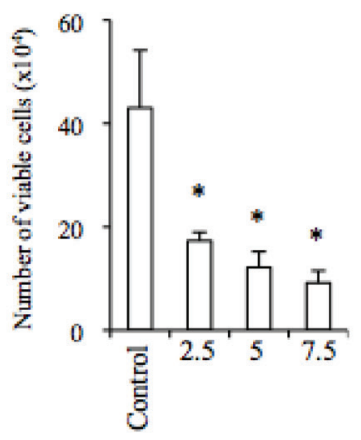

B PANC-1 CSLC
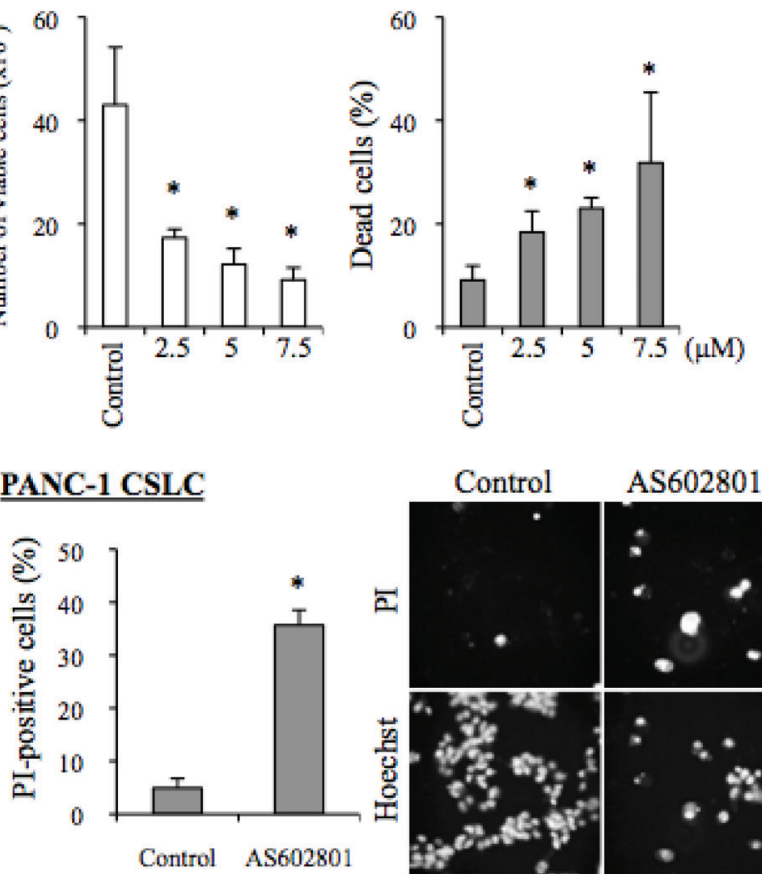

Control

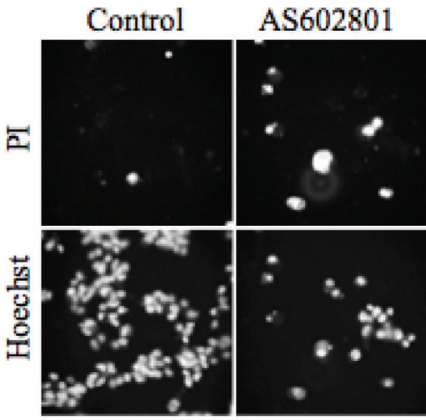

A2780 CSLC

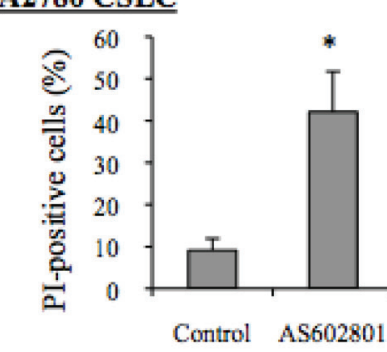

\section{GS-Y01}
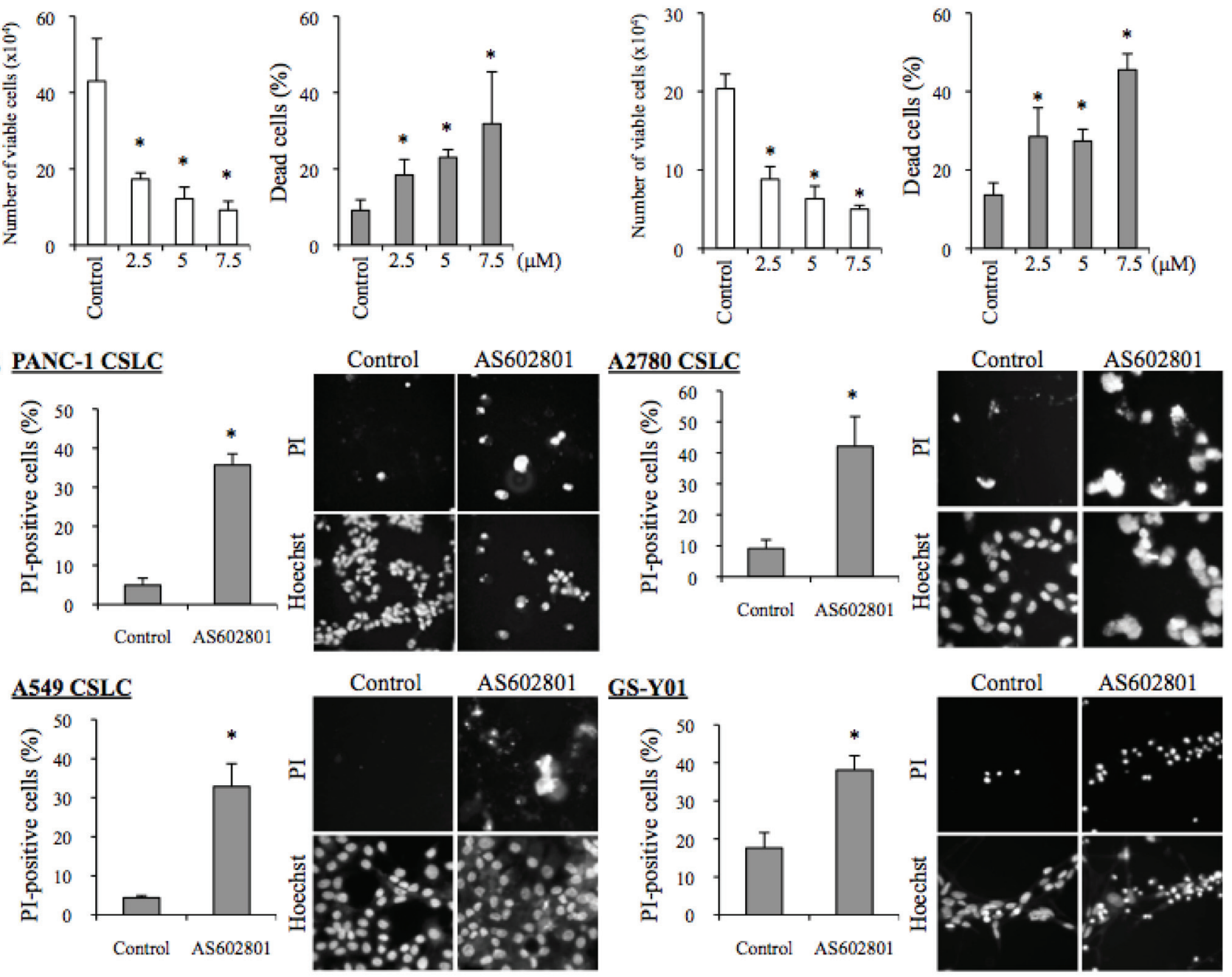

Figure 2: AS602801 has cytotoxic activity against human cancer stem cells. A. Human cancer stem cell lines (PANC-1 CSLC, A2780 CSC, A549 CSLC, and GS-Y01) were treated without (Control) or with the indicated concentrations of AS602801 for 3 days. Numbers of viable cells (left panels) and percentages of dead cells (right panels) were determined using trypan blue as a vital dye. B. Cells were treated without (Control) or with $7.5 \mu \mathrm{M}$ AS602801 for 3 days and then subjected to cell death analysis using propidium iodide (PI) as a vital dye. Left, the percentage of PI-positive (dead) cells relative to Hoechst-positive (total) cells was determined. Right, representative fluorescence images of PI- (upper rows) and Hoechst-positive (lower rows) cells are shown. Values in the graphs represent the mean $+\mathrm{SD}$ from three independent experiments. ${ }^{*} P<0.05$. 
Secondary tumor formation was observed in all but 2 mice (one transplanted with $5 \times 10^{5}$ cells, the other with $2 \times 10^{5}$ cells) transplanted with cells from control-treated tumors, but only in 2 mice transplanted with $1 \times 10^{6}$ cells from AS602801-treated tumors (Figure 5D). Thus, systemic AS602801 treatment reduced the proportion of tumor-initiating cells within the primary tumors. Stem cell marker analysis revealed that Sox2, Nanog, and
Bmi1 levels were reduced in primary tumors treated with AS602801 for 10 days (Figure 5E). Similar to the in vitro results, c-Myc levels in the primary tumors also decreased after AS602801 treatment (Figure 5E). Collectively, these results demonstrated that AS602801 could reduce numbers of tumor-initiating cancer stem cells when administered systemically to tumor-bearing mice.

\section{A}
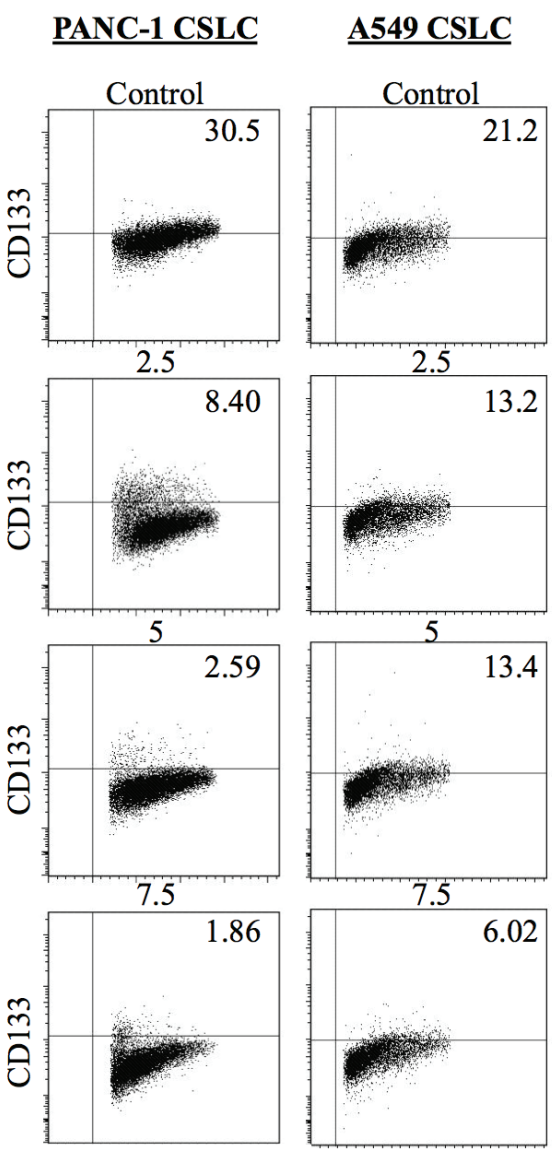

$\underline{\text { A549 CSLC }}$

$\underline{\mathrm{A} 2780 \text { CSLC }}$

GS-Y01
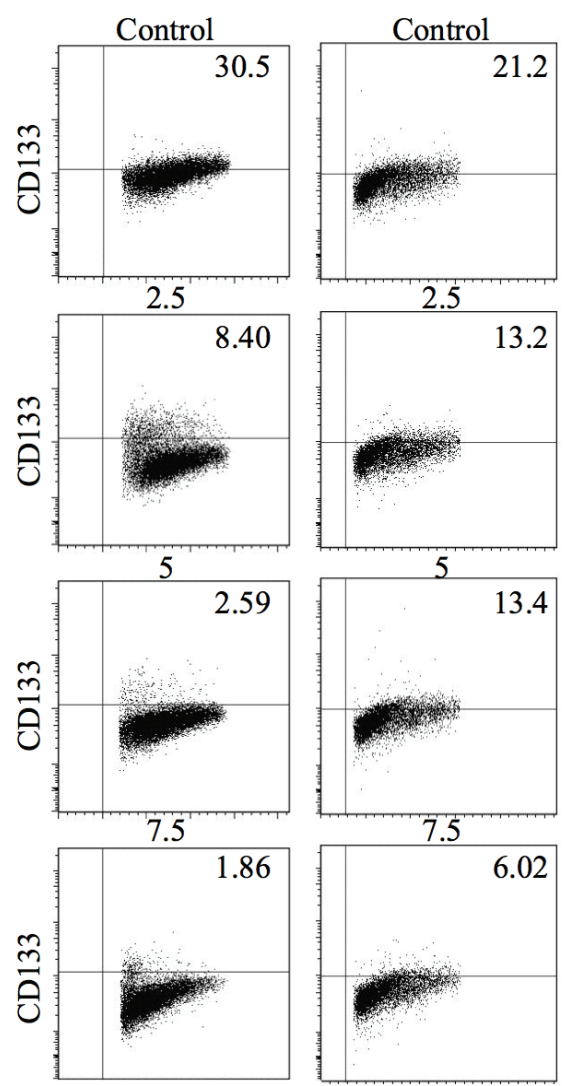

Forward scatter

Forward scatter
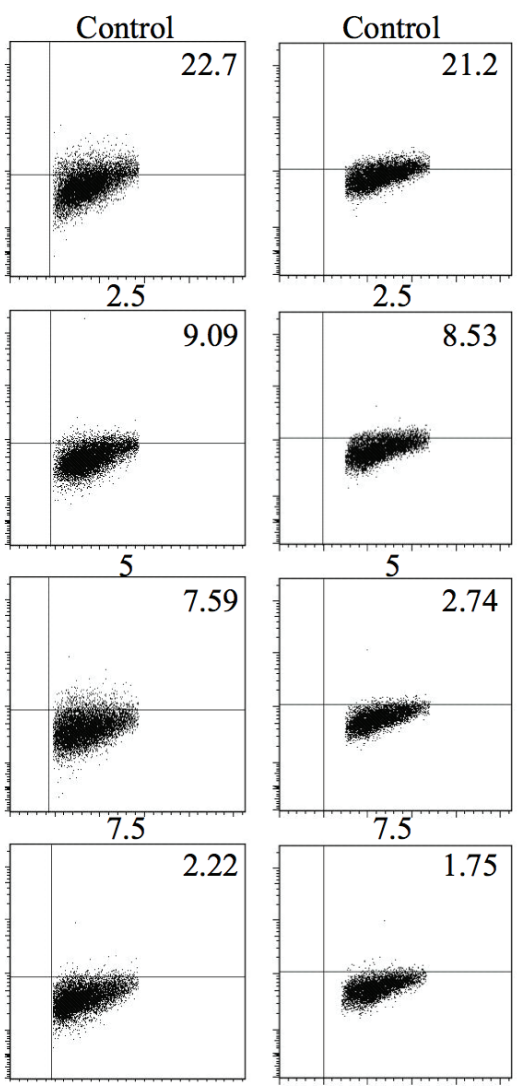

Forward scatter

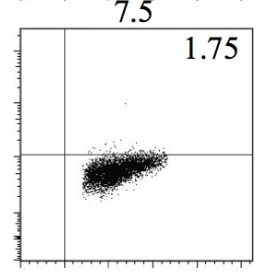

Forward scatter

B

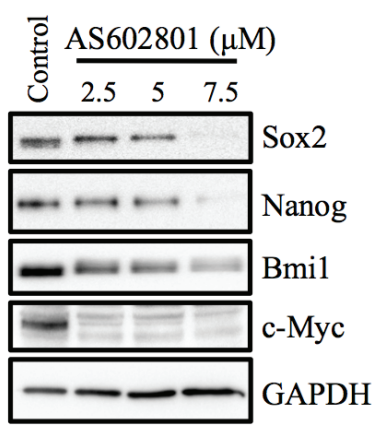

PANC-1 CSLC

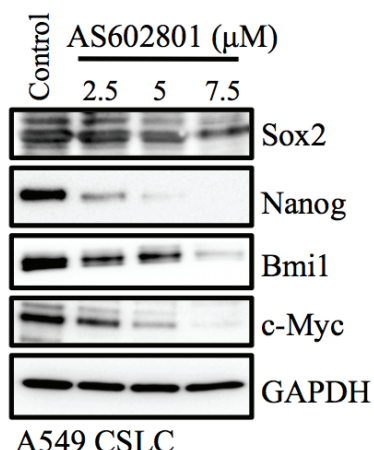

A549 CSLC
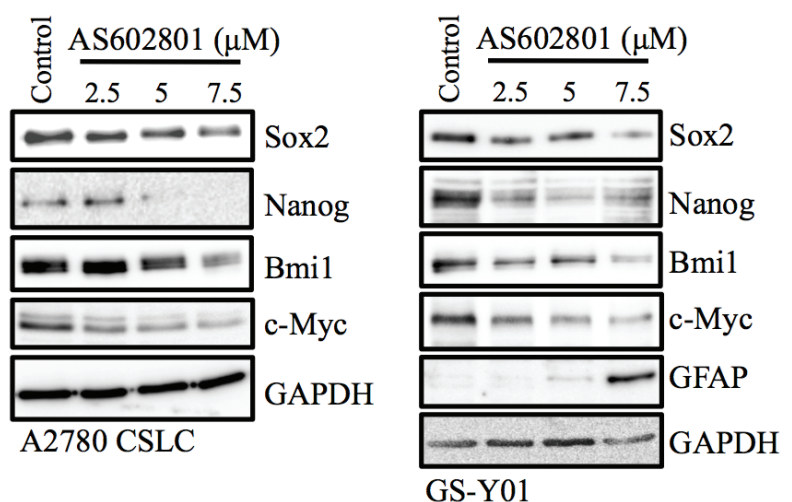

Figure 3: AS602801 treatment causes loss of stem cell marker expression in cancer stem cells. A. Cells cultured without (Control) or with the indicated concentrations of AS602801 for 6 days were subjected to flow cytometric analysis of the cell-surface expression of CD133. Representative flow cytometric plots together with the percentages of CD133-positive cells are shown. B. Cells cultured as described in A. were subjected to immunoblot analysis of the indicated protein levels. 


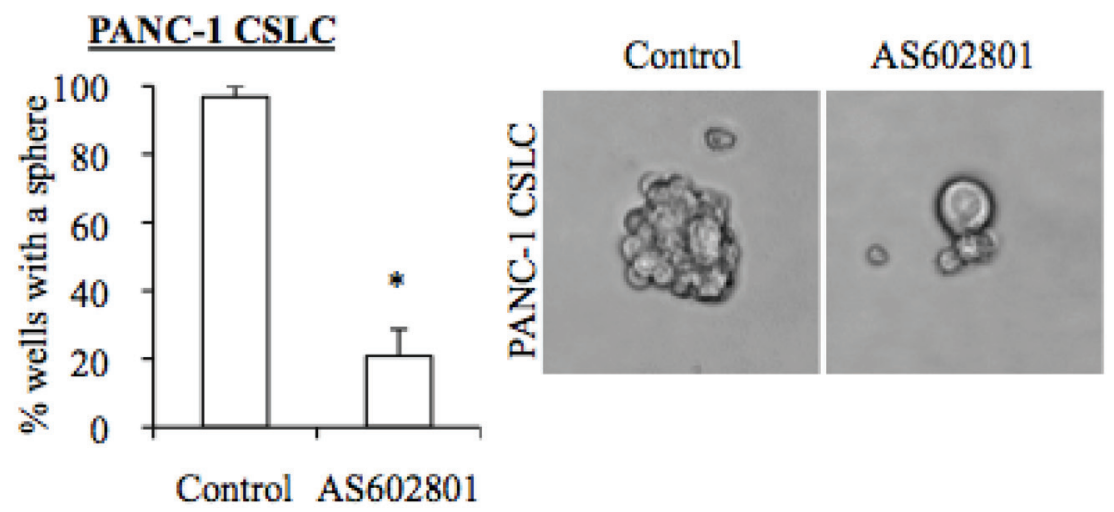

\section{$\underline{A 549 \text { CSLC }}$}
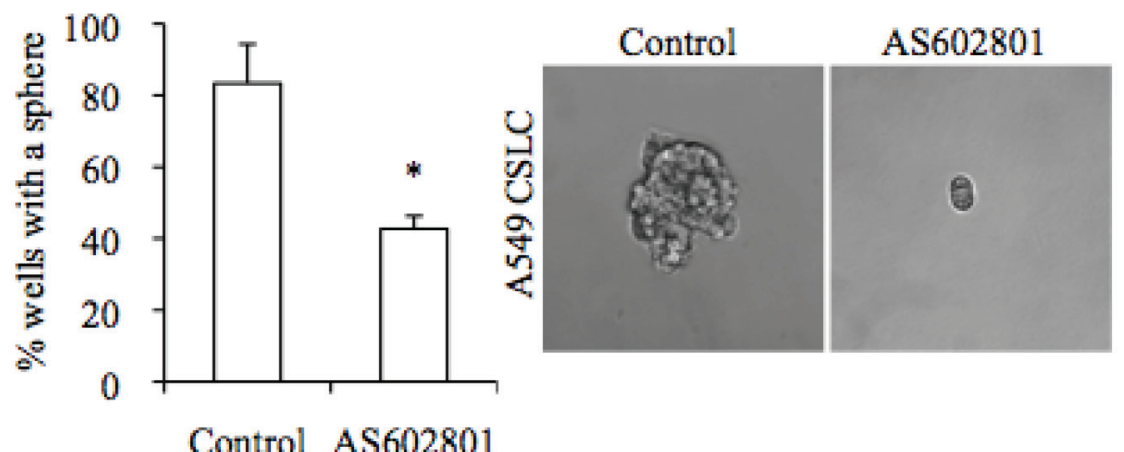

\section{$\underline{\mathrm{A} 2780 \mathrm{CSLC}}$}
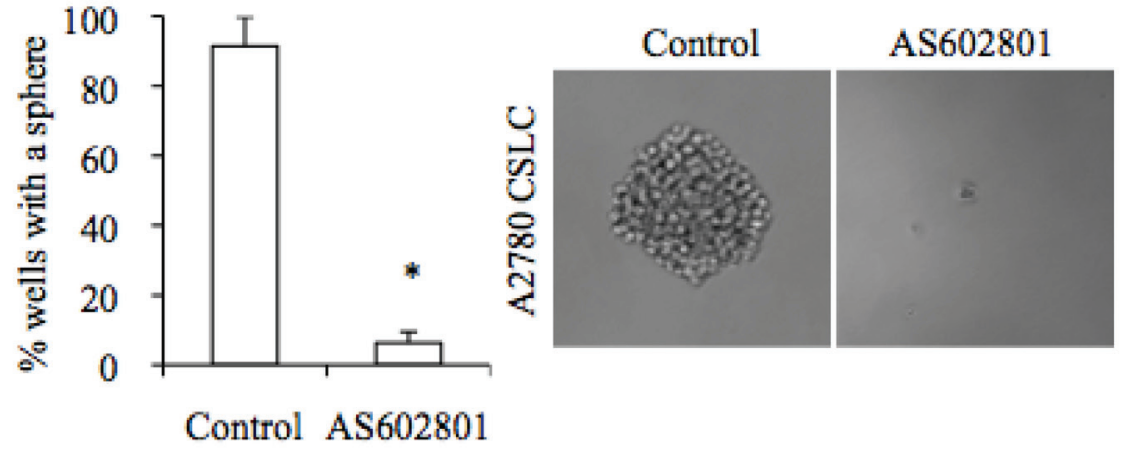

\section{GS-Y01}
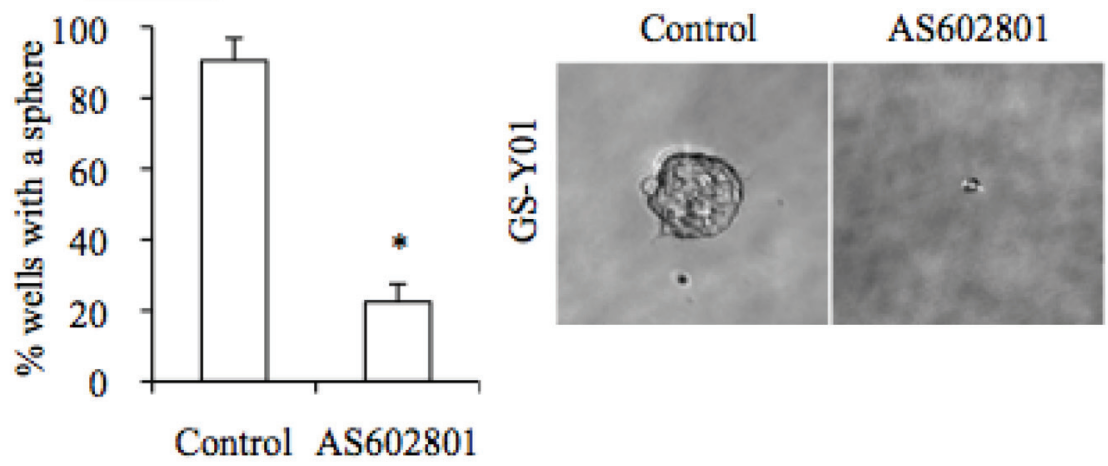

Figure 4: AS602801 induces loss of sphere formation ability in cancer stem cells. Cells cultured without (Control) or with 7.5 $\mu \mathrm{M}$ AS602801 for 6 days were subjected to a sphere formation assay in the absence of AS602801. Right panels show photographs of the representative wells. The graphs show the percentage of the wells where a tumor sphere was formed from a single cell. Values in the graphs represent the mean $+\mathrm{SD}$ from three independent experiments. $* P<0.05$. 
A PANC-1 CSLC

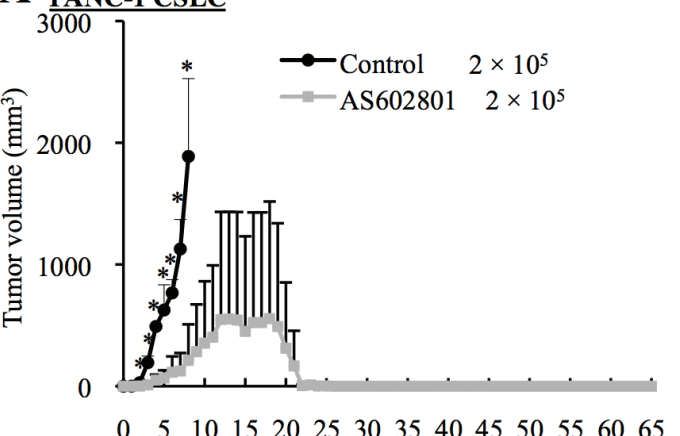

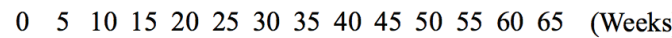

C

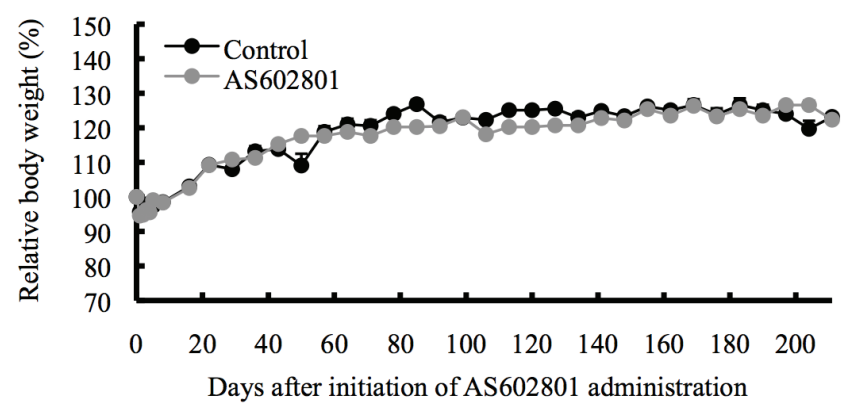

B $\underline{\text { A2780 CSLC }}$

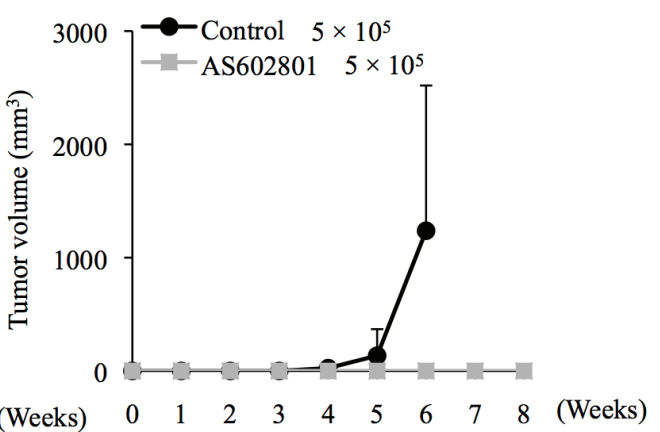

D
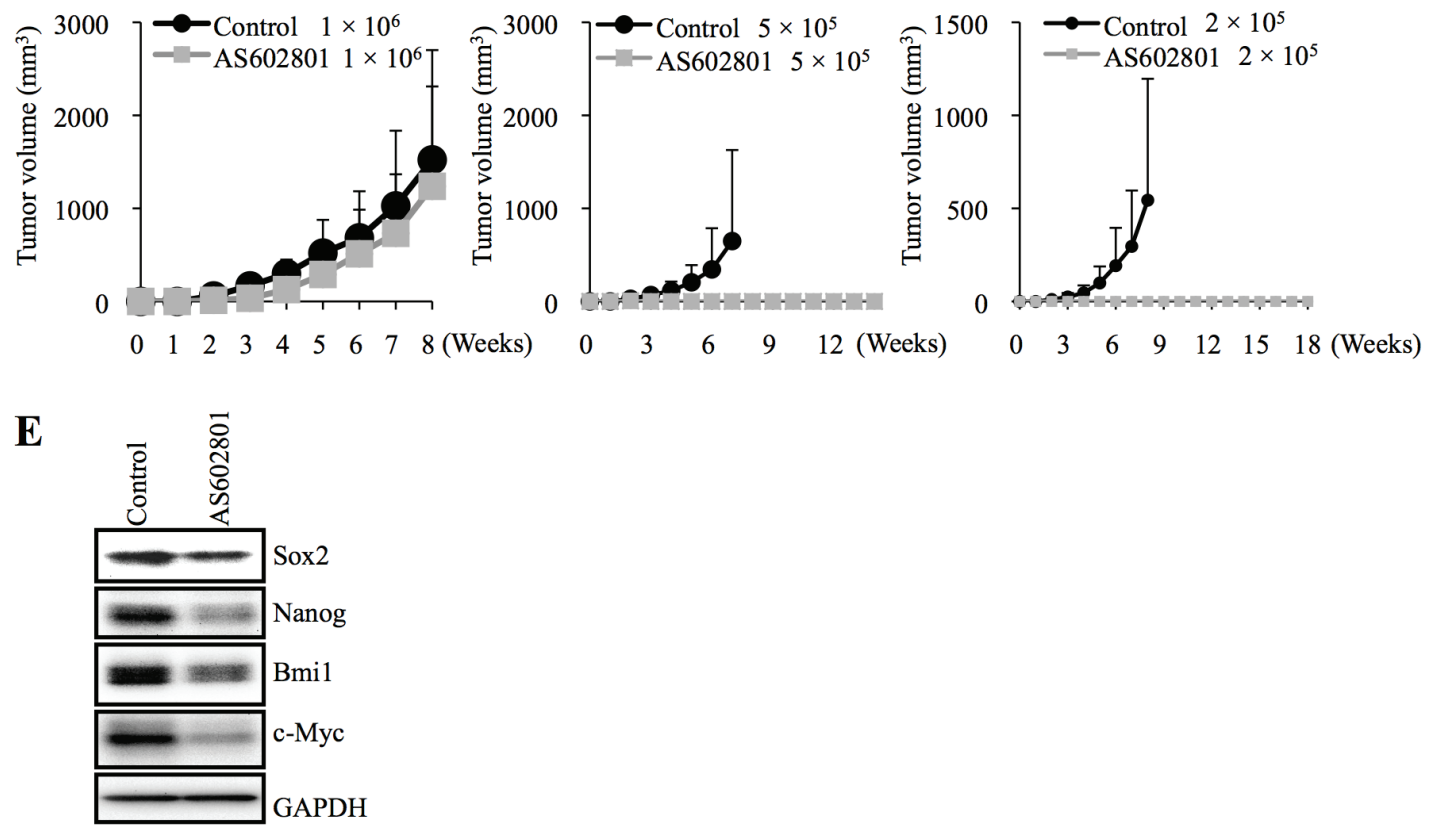

PANC-1

Figure 5: AS602801 treatment inhibits the tumor-initiating capacity of cancer stem cells. A., B. Mice (3 for each group) were implanted subcutaneously with the indicated number of viable PANC-1 CSLCs A. or A2780 CSLCs B. that had been treated with or without AS602801 (7.5 $\mu \mathrm{M}$ for PANC-1 CSLCs, $4 \mu \mathrm{M}$ for A2780 CSLCs) for 6 days. C. Two groups of mice ( 2 mice/group) were given daily intraperitoneal AS602801 injections (40 mg/kg/day) for 10 consecutive days, and their body weight was monitored at the indicated time points. The results are expressed relative to the body weight values recorded at the initial measurement, and represent the mean + SD of the 2 mice in each group. D., E. Mice implanted subcutaneously with PANC-1 CSLCs $\left(1 \times 10^{6}\right.$ viable cells $)$ were randomized into 2 treatment groups ( 4 mice per group) 3 weeks after implantation when the average tumor volume had reached approximately $500 \mathrm{~mm}^{3}$, and received a daily intraperitoneal injection of the control vehicle or AS602801 (40 mg/kg/day) for 10 consecutive days. One day after the final drug treatment, the subcutaneous tumors (primary tumors) were excised and dissociated, and the serial dilutions of the dissociated tumor cells were transplanted subcutaneously into new mice. The volumes of the secondary tumors $(n=3$ for each group) formed by transplantation of the indicated numbers (Left: $1 \times 10^{6}$, Middle: $5 \times 10^{5}$, Right: $2 \times 10^{5}$ ) of viable cells from the primary tumors treated without (control group) or with AS602801 are presented as mean + SD in the graphs D.. Alternatively, the dissociated cells were subjected to immunoblot analysis to measure levels of the indicated proteins $\mathbf{E}$. 


\section{DISCUSSION}

Accumulating evidence from clinical and preclinical studies demonstrates that JNK is a critical molecule in the biology of human cancer and an attractive target of cancer therapy [5-8]. Among currently available JNK inhibitors, SP600125 has been used in the overwhelming majority of studies, but the clinical safety profile of this JNK inhibitor remains unknown [22, 23]. Here, we investigated the anticancer effects of a novel JNK inhibitor, AS602801. Our results showed that AS602801 has cytotoxic activity against both serum-cultured (most likely non-stem) cancer cells and cancer stem cells at a concentration that does not decrease the viability of normal human fibroblasts. AS602801 also inhibited the self-renewal and tumor-initiating capacity of cancer stem cells surviving AS602801 treatment. Most importantly, cancer stem cell numbers in established xenograft tumors were reduced by systemic administration of AS602801 at a dose $(40 \mathrm{mg} / \mathrm{kg})$ and schedule (peritoneal injection once a day for 10 consecutive days) that did not otherwise affect the health of the tumor-bearing mice. In the clinical trial (NCT01630252) testing its safety and efficacy in the treatment of endometriosis, AS602801 (termed PGL5001 in the trial) was given orally to patients at $320 \mathrm{mg} / \mathrm{day}$ $(160 \mathrm{mg} /$ day twice a day) for $8-20$ weeks. Since the human equivalent of the $40 \mathrm{mg} / \mathrm{kg} /$ day AS602801 dose given to mice here is approximately $3.3 \mathrm{mg} / \mathrm{kg} /$ day when calculated based on the $\mathrm{K}_{\mathrm{m}}$ of human and mouse [24], our results suggest that AS602801 was effective in the preclinical xenograft model at a clinically relevant dose. Thus, our findings support the use of AS602801 as a therapeutic agent against cancer stem cells.

JNK is receiving increasing attention as an attractive therapeutic target in various pathological conditions, and more JNK inhibitors are being developed [4, 22, 23]. However, developing clinically-applicable JNK inhibitors is not an easy process. For instance, CC-401 and CC-930 are newly developed JNK inhibitors whose effects and safety were successfully demonstrated in vivo in a variety of liver and kidney disease models [25-31]. However, a clinical trial to determine the optimal dose of CC-401 in the treatment of high-risk myeloid leukemia was prematurely terminated (NCT00126893). Similarly, CC-930 entered clinical trials to test its safety in the treatment of idiopathic pulmonary fibrosis and discoid lupus erythematosus (NCT01203943, NCT01466725), but the trials were terminated because the benefit/risk profile did not justify continuation of the studies. Thus, publicly available clinical trial results indicate that AS602801 is one of a few JNK inhibitors that were successful in human clinical trials.

Unexpectedly, we found in this study that inhibition of JNK by AS602801, as indicated by c-Jun phosphorylation status, was apparently transient and shortlived compared to SP600125-induced inhibition (Figure 6) $[11,32]$. Although it is possible that phosphorylated c-Jun may not accurately reflect JNK activity, and/or that the transient JNK inhibition was just sufficient for cancer stem cell inhibition, it is also possible that AS602801 has a unique off-target effect(s) that also contributes to the inhibition of cancer stem cells. Our data and previous research indicate that JNK inhibitors do not all act the same; they have different inhibitory profiles depending on JNK isoform, different toxicity/safety profiles, and, presumably, different off-target profiles [4, 22, 23]. Investigations of differences between AS602801 and SP600125 in future studies may therefore shed light on new mechanisms by which JNK acts as a therapeutic target to control cancer stem cells. Additionally, the inhibitory effect of AS602801 on overall tumor growth in vivo, in which non-stem cancer cells are important, is yet to be confirmed. Thus, combining AS602801 with chemotherapeutic agents that target non-stem bulk tumor cells might be beneficial in treating cancer.

In conclusion, the present study demonstrates the anticancer effects of AS602801, a drug that has recently been used in a phase 2 clinical trial investigating its

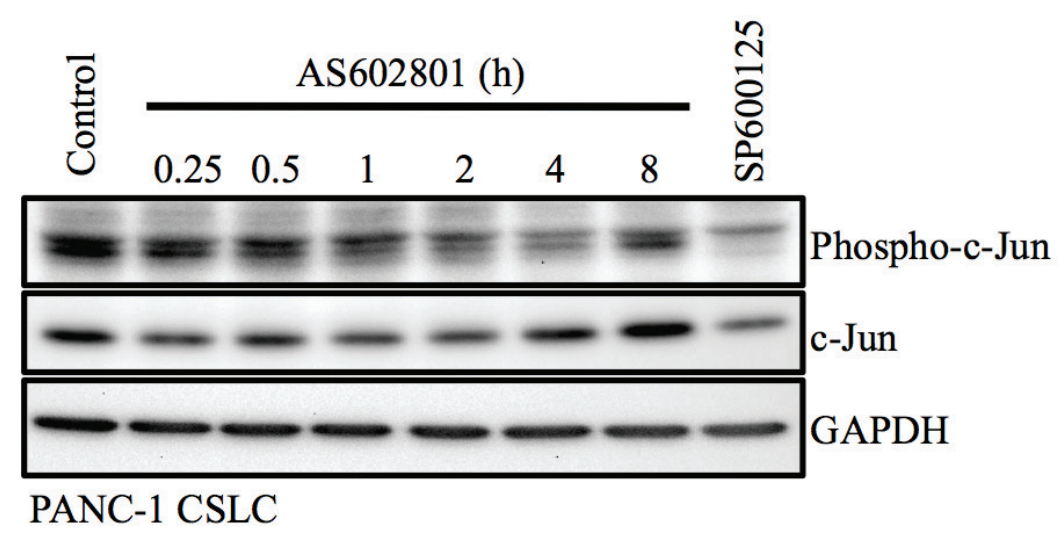

Figure 6: Transient inhibition of c-Jun phosphorylation by AS602801. PANC-1 CSLCs treated with $7.5 \mu \mathrm{M}$ AS602801 for the indicated times or with $20 \mu \mathrm{M}$ SP600125 for $1 \mathrm{~h}$ were subjected to immunoblot analysis to measure levels of the indicated proteins. 
efficacy and safety in the treatment of endometriosis. With the available safety information from the clinical trial and our findings that it can reduce cancer stem cell numbers in vivo, AS602801 could contribute to the development of curative treatments against human cancers. Future investigations are therefore needed to determine whether this endometriosis drug may also be beneficial in the treatment of cancer.

\section{MATERIALS AND METHODS}

\section{Antibodies and reagents}

Antibodies against Sox2 (\#3579), Nanog (\#4903), Bmil (\#6964), GFAP (\#3670), phospho-c-Jun (\#9261), c-Jun (\#9265), and GAPDH (\#5174) were purchased from Cell Signaling Technology Inc. (Beverly, MA, USA). AntiCD133 (W6B3C1) was purchased from Miltenyi Biotech (Bergisch Gladbach, Germany). The antibodies used to detect the expression of Sox2 (MAB2018) and Bmil (05637) in GS-Y01 cells were purchased from R\&D Systems Inc. (Minneapolis, MN, USA) and Millipore (Billerica, MA, USA), respectively. AS602801 was purchased from ChemScene (Monmouth Junction, NJ, USA) and was dissolved in DMSO to prepare a $10 \mathrm{mM}$ stock solution.

\section{Cell culture}

The human pancreatic cancer cell line PANC-1 was obtained from the Cell Resource Center for Biomedical Research, Institute of Development, Aging and Cancer, Tohoku University. The human ovarian cancer cell line A2780 was a kind gift from Dr. T. Tsuruo (Institute of Molecular and Cellular Biosciences, University of Tokyo, Japan) and Drs. R.F. Ozols and T.C. Hamilton (the National Institutes of Health, USA) [33]. The human non-small cell lung cancer cell line A549 was obtained from the Riken BioResource Center. These cell lines were maintained in DMEM/F12 medium supplemented with $10 \%$ fetal bovine serum (FBS; Sigma) [11-13]. Normal human IMR90 fetal lung fibroblasts were obtained from ATCC and maintained in DMEM supplemented with 10\% FBS. Furthermore, the culture medium was supplemented with $100 \mathrm{U} / \mathrm{mL}$ penicillin and $100 \mu \mathrm{g} / \mathrm{mL}$ streptomycin. The establishment of human cancer stem cells used in this study (GS-Y01, PANC-1 CSLCs, A2780 CSLCs, and A549 CSLCs) has been described elsewhere [11-13, 34]. These cell lines were maintained under the monolayer stem cell culture condition as previously reported [11$13,34]$. Briefly, cells were cultured on collagen-I-coated dishes (IWAKI, Tokyo, Japan) in the stem cell culture medium (DMEM/F12 medium supplemented with $1 \%$ B27 [Gibco-BRL, Carlsbad, CA, USA], 20 ng/mL EGF and FGF2 [Peprotech Inc., Rocky Hill, NJ, USA], D-(+)- glucose [final concentration, $26.2 \mathrm{mM}$ ], L-glutamine [final concentration, $4.5 \mathrm{mM}$ ], 100 units/mL penicillin, and $100 \mu \mathrm{g} / \mathrm{mL}$ streptomycin). Stem cell culture medium was changed approximately every 3 days, and EGF and FGF2 were added to the culture medium every day. The authenticity of PANC-1 CSLCs, A2780 CSLCs, and A549 CSLCs was verified by the genotyping of short tandem repeat (STR) loci (Bio-Synthesis Inc., Lewisville, TX, USA) followed by comparison to the ATCC STR database (http://www.atcc.org/STR_Database.aspx) for Human Cell Lines. All IMR90 experiments were performed using low passage number $(<8)$ cells.

\section{Cytotoxicity assay}

Viable and dead cells were identified by their ability and inability to exclude vital dyes, respectively $[32,35]$. Briefly, cells were stained with $0.2 \%$ trypan blue for $1 \mathrm{~min}$ at room temperature (RT), and the number of viable and dead cells was determined using a hemocytometer. The percentage of dead cells was defined as $100 \times$ (number of dead cells/[the number of viable + dead cells]). Alternatively, cells were incubated in situ with propidium iodide (PI; $1 \mu \mathrm{g} / \mathrm{mL})$ and Hoechst $33342(10 \mu \mathrm{g} / \mathrm{ml})$ for $10 \mathrm{~min}$ at $37^{\circ} \mathrm{C}$ in a $\mathrm{CO}_{2}$ incubator to stain the dead cells and cell nuclei, respectively. Subsequently, the numbers of PI- and Hoechst-positive cells were scored under a fluorescence microscope (CKX41; Olympus, Tokyo, Japan), and the percentage of PI-positive cells (dead cells) relative to Hoechst-positive cells (total cells) was determined.

\section{Flow cytometric analysis}

Flow cytometric analysis was conducted as previously described [11]. Dissociated cells were washed with ice-cold phosphate-buffered saline (PBS), fixed with $4 \%(\mathrm{w} / \mathrm{v})$ paraformaldehyde for $10 \mathrm{~min}$ at RT, and washed again with PBS. The cells were blocked in FCM buffer $(0.5 \%[\mathrm{w} / \mathrm{v}]$ bovine serum albumin, $0.1 \%[\mathrm{w} / \mathrm{v}]$ $\mathrm{NaN}_{3}$ in PBS) for $1 \mathrm{~h}$, followed by three PBS rinses and further incubation with anti-CD133 antibody in the FCM buffer overnight at $4{ }^{\circ} \mathrm{C}$ and then with the Alexa Fluor ${ }^{\circledR}$ 488 goat anti-mouse IgG for another $1 \mathrm{~h}$ at RT. Gating for single cells was established using forward scatter in the isotype control samples. The isotype control samples were used to establish a gate in the fluorescein isothiocyanate (FITC) channel. Cells showing a signal for CD133 above the gate established by the isotype control were deemed CD133-positive. All flow cytometric analysis experiments were run on the FACSCanto ${ }^{\mathrm{TM}}$ II Flow Cytometer (BD Biosciences, Franklin Lakes, NJ, USA). 


\section{Immunoblot analysis}

Immunoblot analysis was conducted as previously described [11]. Briefly, cells were washed with icecold PBS and lysed in RIPA buffer $(10 \mathrm{mM}$ Tris- $\mathrm{HCl}$ [pH 7.4], 0.1\% SDS, $0.1 \%$ sodium deoxycholate, $1 \%$ NP-40, $150 \mathrm{mM} \mathrm{NaCl}, 1 \mathrm{mM}$ EDTA, $1.5 \mathrm{mM} \mathrm{Na}_{3} \mathrm{VO}_{4}$, $10 \mathrm{mM} \mathrm{NaF}, 10 \mathrm{mM}$ sodium pyrophosphate, $10 \mathrm{mM}$ sodium $\beta$-glycerophosphate, and $1 \%$ protease inhibitor cocktail set III [Sigma]). After centrifugation for $10 \mathrm{~min}$ at $14,000 \times \mathrm{g}$ at $4^{\circ} \mathrm{C}$, the supernatants were recovered as cell lysates, and the protein concentration of the cell lysates was determined by a BCA protein assay kit (Pierce Biotechnology Inc., Rockford, IL, USA). Cell lysates containing equal amounts of protein were separated by SDS-PAGE and transferred to a polyvinylidene difluoride membrane. The membrane was probed with a primary antibody and then with an appropriate HRPconjugated secondary antibody, according to the protocol recommended by the manufacturer of each antibody. Immunoreactive bands were visualized using Immobilon Western Chemiluminescent HRP Substrate (Millipore).

\section{Sphere formation assay}

The sphere formation assay was performed as previously described [11, 13]. After dissociation, single cells were serially diluted in the stem cell culture medium and seeded into non-coated 96-well plates such that each well contained a single cell. Wells containing a single cell were marked under a phase-contrast microscope on the next day, and 1 week after seeding, the percentage of marked wells with a sphere relative to the total number of marked wells was determined.

\section{Mouse studies}

Mouse xenograft studies were conducted essentially as previously described [11, 36]. For subcutaneous implantation, 6- to 9-week-old male BALB/cAJcl-nu/nu mice (CLEA Japan Inc., Tokyo, Japan) were implanted subcutaneously in the flank region with cells suspended in $200 \mu \mathrm{L}$ of sterilized PBS under avertin $(0.375 \mathrm{~g} /$ $\mathrm{kg}$ intraperitoneally) anesthesia. After implantation, the recipient mice were monitored for general health status and presence of subcutaneous tumors. For serial transplantation, primary tumors treated as described in the figure legend were excised, and, after a wash in chilled sterile PBS, were transferred into DMEM/F12, minced with scissors, and incubated in Accutase (Sigma) for $30 \mathrm{~min}$ at $37^{\circ} \mathrm{C}$. After being rinsed with DMEM/F12, the cells were resuspended in DMEM/F12 and filtered through a $70-\mu \mathrm{m}$ strainer. The single cell suspension was then subcutaneously injected after cell number and viability were determined. Alternatively, the cells were analyzed for the expression of stem cell-related proteins by immunoblotting. For systemic administration of AS602801, the AS602801 stock solution $(10 \mathrm{mM}$ in DMSO) was diluted in PBS to prepare $200 \mu \mathrm{L}$ solutions for each injection. The AS602801 solutions were injected intraperitoneally into nude mice. All control- and AS602801-treated mice received an equal volume of DMSO per body weight $(3.6 \mathrm{~mL} / \mathrm{kg})$. Tumor volume was determined by measuring tumor diameters (measurement of 2 perpendicular axes of tumors) using a caliper and calculated as $1 / 2 \times($ larger diameter $) \times(\text { smaller diameter })^{2}$. All animal experiments were performed under a protocol approved by the Animal Research Committee of Yamagata University.

\section{Statistical analysis}

Results are expressed as the mean + standard deviation (SD), and differences were compared using the two-tailed Student's $t$-test. $P$-values $<0.05$ were considered statistically significant and are indicated with asterisks in the figures.

\section{ACKNOWLEDGMENTS}

We thank Ms. Eriko Watanabe and Ms. Asuka Sugai for their technical and secretarial contributions to this study, respectively. This work was supported by Grants-inAid for Scientific Research, for Challenging Exploratory Research, and for Young Scientists from the Ministry of Education, Culture, Sports, Science and Technology of Japan, by a Grant-in-Aid from the Global COE Program of the Japan Society for the Promotion of Science, by the National Cancer Center Research and Development Fund (23-A-20), and by a grant from the Japan Brain Foundation.

\section{CONFLICTS OF INTEREST}

The authors declare no conflict of interest.

\section{REFERENCES}

1. Davis RJ. Signal transduction by the JNK group of MAP kinases. Cell. 2000; 103:239-252.

2. Sehgal V and Ram PT. Network Motifs in JNK Signaling. Genes Cancer. 2013; 4:409-413. doi: 10.1177/1947601913507577.

3. Weston CR and Davis RJ. The JNK signal transduction pathway. Curr Opin Cell Biol. 2007; 19:142-149.

4. Bubici C and Papa S. JNK signalling in cancer: in need of new, smarter therapeutic targets. Br J Pharmacol. 2014; 171:24-37. 
5. Dhanasekaran DN. JNK Signaling Network and Cancer. Genes Cancer. 2013; 4:332-333. doi: $10.1177 / 1947601913507949$.

6. Kennedy NJ and Davis RJ. Role of JNK in tumor development. Cell Cycle. 2003; 2:199-201.

7. Manning AM and Davis RJ. Targeting JNK for therapeutic benefit: from junk to gold? Nat Rev Drug Discov. 2003; 2:554-565.

8. Wagner EF and Nebreda AR. Signal integration by JNK and p38 MAPK pathways in cancer development. Nat Rev Cancer. 2009; 9:537-549.

9. Kitanaka C, Sato A and Okada M. JNK Signaling in the Control of the Tumor-Initiating Capacity Associated with Cancer Stem Cells. Genes Cancer. 2013; 4:388-396. doi: 10.1177/1947601912474892.

10. Matsuda K, Sato A, Okada M, Shibuya K, Seino S, Suzuki K, Watanabe E, Narita Y, Shibui S, Kayama T and Kitanaka C. Targeting JNK for therapeutic depletion of stem-like glioblastoma cells. Sci Rep. 2012; 2:516.

11. Okada M, Shibuya K, Sato A, Seino S, Suzuki S, Seino M and Kitanaka C. Targeting the K-Ras-JNK axis eliminates cancer stem-like cells and prevents pancreatic tumor formation. Oncotarget. 2014; 5:5100-5112. doi: 10.18632/ oncotarget.2087.

12. Okada M, Shibuya K, Sato A, Seino S, Watanabe E, Suzuki S, Seino M and Kitanaka C. Specific role of JNK in the maintenance of the tumor-initiating capacity of A549 human non-small cell lung cancer cells. Oncol Rep. 2013; 30:1957-1964.

13. Seino M, Okada M, Shibuya K, Seino S, Suzuki S, Ohta T, Kurachi $\mathrm{H}$ and Kitanaka C. Requirement of JNK signaling for self-renewal and tumor-initiating capacity of ovarian cancer stem cells. Anticancer Res. 2014; 34:4723-4731.

14. Bennett BL. c-Jun N-terminal kinase-dependent mechanisms in respiratory disease. Eur Respir J. 2006; 28:651-661.

15. Ferrandi C, Richard F, Tavano P, Hauben E, Barbie V, Gotteland JP, Greco B, Fortunato M, Mariani MF, Furlan R, Comi G, Martino G and Zaratin PF. Characterization of immune cell subsets during the active phase of multiple sclerosis reveals disease and c-Jun N-terminal kinase pathway biomarkers. Mult Scler. 2011; 17:43-56.

16. Grosse-Gehling P, Fargeas CA, Dittfeld C, Garbe Y, Alison MR, Corbeil D and Kunz-Schughart LA. CD133 as a biomarker for putative cancer stem cells in solid tumours: limitations, problems and challenges. J Pathol. 2013; 229:355-378.

17. Irollo E and Pirozzi G. CD133: to be or not to be, is this the real question? Am J Transl Res. 2013; 5:563-581.

18. Moghbeli M, Moghbeli F, Forghanifard MM and Abbaszadegan MR. Cancer stem cell detection and isolation. Med Oncol. 2014; 31:69.

19. Chappell J and Dalton S. Roles for MYC in the establishment and maintenance of pluripotency. Cold
Spring Harb Perspect Med. 2013; 3:a014381.

20. Wang J, Wang H, Li Z, Wu Q, Lathia JD, McLendon $\mathrm{RE}$, Hjelmeland $\mathrm{AB}$ and Rich JN. c-Myc is required for maintenance of glioma cancer stem cells. PLoS One. 2008; 3:e3769.

21. Zheng H, Ying H, Yan H, Kimmelman AC, Hiller DJ, Chen AJ, Perry SR, Tonon G, Chu GC, Ding Z, Stommel JM, Dunn KL, Wiedemeyer R, You MJ, Brennan C, Wang YA, et al. Pten and p53 converge on c-Myc to control differentiation, self-renewal, and transformation of normal and neoplastic stem cells in glioblastoma. Cold Spring Harb Symp Quant Biol. 2008; 73:427-437.

22. Bogoyevitch MA and Arthur PG. Inhibitors of c-Jun N-terminal kinases: JuNK no more? Biochim Biophys Acta. 2008; 1784:76-93.

23. Bogoyevitch MA, Ngoei KR, Zhao TT, Yeap YY and $\mathrm{Ng}$ DC. c-Jun N-terminal kinase (JNK) signaling: recent advances and challenges. Biochim Biophys Acta. 2010; 1804:463-475.

24. Reagan-Shaw S, Nihal M and Ahmad N. Dose translation from animal to human studies revisited. FASEB J. 2008; 22:659-661.

25. Kanellis J, Ma FY, Kandane-Rathnayake R, Dowling JP, Polkinghorne KR, Bennett BL, Friedman GC and NikolicPaterson DJ. JNK signalling in human and experimental renal ischaemia/reperfusion injury. Nephrol Dial Transplant. 2010; 25:2898-2908.

26. Lim AK, Ma FY, Nikolic-Paterson DJ, Ozols E, Young MJ, Bennett BL, Friedman GC and Tesch GH. Evaluation of JNK blockade as an early intervention treatment for type 1 diabetic nephropathy in hypertensive rats. Am J Nephrol. 2011; 34:337-346.

27. Ma FY, Flanc RS, Tesch GH, Bennett BL, Friedman GC and Nikolic-Paterson DJ. Blockade of the c-Jun amino terminal kinase prevents crescent formation and halts established anti-GBM glomerulonephritis in the rat. Lab Invest. 2009; 89:470-484.

28. Ma FY, Flanc RS, Tesch GH, Han Y, Atkins RC, Bennett BL, Friedman GC, Fan JH and Nikolic-Paterson DJ. A pathogenic role for c-Jun amino-terminal kinase signaling in renal fibrosis and tubular cell apoptosis. J Am Soc Nephrol. 2007; 18:472-484.

29. Reich N, Tomcik M, Zerr P, Lang V, Dees C, Avouac J, Palumbo K, Horn A, Akhmetshina A, Beyer C, Xie W, Bennett BL, Distler O, Schett G and Distler JH. Jun $\mathrm{N}$-terminal kinase as a potential molecular target for prevention and treatment of dermal fibrosis. Ann Rheum Dis. 2012; 71:737-745.

30. Uehara T, Bennett B, Sakata ST, Satoh Y, Bilter GK, Westwick JK and Brenner DA. JNK mediates hepatic ischemia reperfusion injury. J Hepatol. 2005; 42:850-859.

31. Uehara T, Xi Peng X, Bennett B, Satoh Y, Friedman G, Currin R, Brenner DA and Lemasters J. c-Jun N-terminal kinase mediates hepatic injury after rat liver transplantation. 
Transplantation. 2004; 78:324-332.

32. Suzuki S, Okada M, Shibuya K, Seino M, Sato A, Takeda H, Seino S, Yoshioka T and Kitanaka C. JNK suppression of chemotherapeutic agents-induced ROS confers chemoresistance on pancreatic cancer stem cells. Oncotarget. 2015; 6:458-470. doi: 10.18632/ oncotarget.2693.

33. Hamilton TC, Winker MA, Louie KG, Batist G, Behrens BC, Tsuruo T, Grotzinger KR, McKoy WM, Young RC and Ozols RF. Augmentation of adriamycin, melphalan, and cisplatin cytotoxicity in drug-resistant and -sensitive human ovarian carcinoma cell lines by buthionine sulfoximine mediated glutathione depletion. Biochem Pharmacol. 1985; 34:2583-2586.

34. Sato A, Sunayama J, Okada M, Watanabe E, Seino S, Shibuya K, Suzuki K, Narita Y, Shibui S, Kayama T and
Kitanaka C. Glioma-initiating cell elimination by metformin activation of FOXO3 via AMPK. Stem Cells Transl Med. 2012; 1:811-824.

35. Okada M, Sato A, Shibuya K, Watanabe E, Seino S, Suzuki S, Seino M, Narita Y, Shibui S, Kayama T and Kitanaka C. JNK contributes to temozolomide resistance of stem-like glioblastoma cells via regulation of MGMT expression. Int J Oncol. 2014; 44:591-599.

36. Shibuya K, Okada M, Suzuki S, Seino M, Seino S, Takeda $\mathrm{H}$ and Kitanaka $\mathrm{C}$. Targeting the facilitative glucose transporter GLUT1 inhibits the self-renewal and tumorinitiating capacity of cancer stem cells. Oncotarget. 2015; 6:651-661. doi: 10.18632/oncotarget.2892. 